\title{
LIKE IN SIMILES - A RELEVANCE-THEORETIC VIEW
}

\author{
EWA WALASZEWSKA \\ Institute of English Studies, University of Warsaw \\ e.walaszewska@uw.edu.pl
}

\begin{abstract}
The paper examines the meaning of like as used in similes in the light of relevance theory. Similes, even though superficially indistinguishable from literal comparisons, are found to be closer to metaphors. Therefore, it is proposed that like in similes is different from like employed in literal comparisons. In particular, it is claimed that, contrary to the current relevance-theoretic position on this issue, like in similes introduces an ad hoc concept. This like is seen as both conceptual and procedural and, as such, it is distinct from both the conceptual like used in literal comparisons and the procedural like functioning as a pragmatic marker. Such a solution accounts for the similarities and differences between similes, metaphors and literal comparisons.
\end{abstract}

\section{Introduction}

Similes would be metaphors were it not for the word like. The paper is an attempt to throw some light on the meaning of like as used in similes. Even though they bear a superficial resemblance to literal comparisons, similes are actually closer to metaphors. Unlike literal comparisons, they are irreversible and they can give rise to similar effects as corresponding metaphors. Consequently, similes are assumed to be related to metaphors. To account for this relation, after examining previous approaches to the problem, it is proposed that like in similes involves both conceptual meaning following from the original concept of similarity and a procedural instruction to create an ad hoc concept.

\section{Simile and literal comparison}

Most definitions of simile describe it as involving "an explicit comparison between two things or actions" signalled, in the majority of cases, by the presence of like (Cruse 2006: 165). In comparison, one examines the things being compared in order to find out whether they are similar or different, and in what respects these things are similar or not (Bredin 1998: 69). From this it follows that there are two types of comparison: open, which do not mention properties with respect to which the two compared things are alike or different, and closed, which are comparisons that explicitly point to such properties (Bredin 1998: 70, 72; see also Beardsley 1981). Consequently, there are two corresponding types of simile: open, e.g. Her heart is like stone and closed, e.g. Her 
heart is hard like stone (Bredin 1998; Margolis 1957: 187; see also Beardsley 1981). On the basis of the above examples, it is possible to say that open similes have the form $X$ is like $Y$, and closed similes state "that $\mathrm{X}$ is like $\mathrm{Y}$ in such and such a respect" (Beardsley 1981: 137). Closed similes specify "the respects in which the comparison is intended", and hence neutralize - though do not eliminate - the figurativeness of the simile (Margolis 1957: 187). For Beardsley (1981: 138), open similes are "empty and uncontrolled" out of context; it is the context that is needed to show in what respects $\mathrm{X}$ is like $Y$. This paper will focus on open similes of the $X$ is like $Y$ form.

However, not all comparison statements of the form $X$ is like $Y$ are regarded as similes; many authors agree that there are two kinds of such statements, dependent on the type of similarity exhibited. Two much discussed examples originally given by Ortony (1993: 346-347) illustrate the difference between literal and non-literal similarity:

(1) Encyclopaedias are like dictionaries.

(2) Encyclopaedias are like gold mines.

Example (1) involves literal similarity, since the comparison emphasises some properties shared by encyclopaedias and dictionaries which are salient for both types of books, such as being used for reference and being organised in alphabetical order. On the other hand, example (2) involves non-literal similarity because the properties shared by the two types of entities seem hardly salient and more abstract, e.g. 'being profitable' (Ortony 1993: 347; see also Levinson 1983: 155). Consequently, statements involving literal similarity may be referred to as 'literal comparisons' (Levinson 1983; Ortony 1993) or 'statements of similarity' (Croft and Cruse 2004). Statements involving non-literal similarity can be called 'similes' (Croft and Cruse 2004) or 'non-literal comparisons' (Ortony 1993).

It is also possible to show the difference between literal comparisons and similes by resorting to the distinction between symmetrical comparisons and predicative comparisons (Bredin 1998: 74). A symmetrical comparison is defined as asserting or denying "a likeness between two things in such a way that each identifies the other" (Bredin 1998: 74, italics in the original); in other words, in a symmetrical comparison, the subject and the predicate are referentially independent of each other. In (1), the denotation of the term encyclopaedias is distinct from the denotation of the term dictionaries so this example involves a symmetrical comparison. This also implies that statements involving a symmetrical comparison are reversible without (much) change in meaning, which agrees with the observation that literal comparisons are generally reversible (see Glucksberg \& Keysar 1993: 414). On the other hand, "[a] predicative comparison asserts or denies a likeness between two things in such a way that one of them describes the other" (Bredin 1998: 74, italics in the original) - the subject refers to something which is then described by the predicate. Therefore, an interchange of the subject and its predicate will bring about a major change in meaning. In (2), the expression gold mines serves as a description of encyclopaedias. Interchanging the subject with its predicate will result in a major change in meaning, for example Gold mines are like encyclopaedias may be interpreted as 'gold mines are so organised that you can easily find what you are looking for', etc. 
Croft and Cruse (2004: 211) suggest a different diagnostic test with which it is possible to check whether a given statement of comparison is a literal comparison or a simile. The test consists in transforming a comparison statement of the form $X$ is like $Y$ into the corresponding nominal metaphor of the form $X$ is $Y$. While, in the case of literal comparisons, such a transformation results in unacceptability or in a major change in meaning, similes undergo this process without a great difference in meaning. Consequently, the meaning of the simile in (2) is close to that of the corresponding metaphor in (3), whereas the meaning of the literal comparison in (1) is not preserved in the corresponding $X$ is $Y$ form in (4).

3) Encyclopaedias are gold mines.

4) Encyclopaedias are dictionaries.

\section{Simile and metaphor}

With respect to form, similes are identical to literal comparison statements; with respect to meaning, they are close to corresponding nominal metaphors, as shown by the simile in (2) and the metaphor in (3). If similes and their corresponding metaphors can give rise to similar, or even the same, interpretations, then the question is whether they are related (for discussion, see e.g. Israel, Riddle Harding \& Tobin 2004). One possible answer comes from the so called comparison theory of metaphor, the tradition extending from Cicero or Quintilian to Miller (1993), according to which metaphors are implicit similes (elliptical similes). This means that in order to understand a metaphor of the form $X$ is $Y$, which is false on a literal interpretation, one has to transform it into the corresponding simile, $X$ is like $Y$, which will always be true when taken literally.

Another possible answer was already hinted at by Aristotle, whose observation that "[similes] are metaphors, differing in the form of expression" (Rhetoric 3.4.2, italics in the original) boils down to a bold statement that both metaphors and similes involve non-literal (metaphorical) meaning, with the difference being the presence of like in similes. Very much in the tradition of Aristotle, Ricoeur (2003: 293) views simile as not fundamentally different from metaphor: he claims that it is only a weakened version of metaphor. Lakoff and Turner (1989: 133) likewise claim that metaphor and simile are essentially versions of the same phenomenon in that both metaphorical statements and simile statements "can employ conceptual metaphor". Following their argument, we may assume that examples (2) and (3) use basically the same conceptual metaphor, the only difference being that the simile makes a weaker claim. Thus in both cases, one concept (ENCYCLOPAEDIAS) is being understood in terms of another (GOLD MINES), and the form of an utterance has very little bearing on whether metaphor is involved in the comprehension process. The fact that it is the conceptual nature of metaphor that is emphasised, not its linguistic realizations, shows that, for Lakoff and Turner, there is no essential difference between metaphor and simile.

Still another possibility, though related to the previous one, is that similes are implicit metaphors (e.g. Glucksberg 2001). ${ }^{1}$ On this approach, all statements of the form $X$ is $Y$, literal or metaphorical, are understood as class-inclusion statements. For example, a literal statement like $A$ louse is an insect is a class-inclusion statement in that it 
ascribes to any louse the membership in the category of insects. In the nominal metaphor John is a louse, John belongs to the (more abstract) superordinate category of which the louse is a perfect exemplar, that is, the category of contemptible beings capable of odious low conduct. In Glucksberg's terms, via the mechanism of dual reference, the metaphor simultaneously refers to the literal louse as the perfect representative of the extended category and classifies John as a member of this category, with the resulting meaning that John is a contemptible being capable of odious low conduct. On this view, the corresponding simile John is like a louse involves the literal louse and can only be understood when transformed into the metaphor form. This transformation will allow for constructing the superordinate category whose features will be ascribed to John.

It is also possible to claim that metaphors and similes are distinct. This position has been assumed in cognitive linguistics by Croft and Cruse (2004: 212), who claim: "The first and most obvious difference is in propositional structure. An expression of the form $A$ is like $B$ asserts that there is a resemblance between $\mathrm{A}$ and $\mathrm{B}$ in some respect. An expression of the form $A$ is $B$, on the other hand, predicates certain properties directly of A". The position that metaphors and similes are distinct seems to have also been adopted by relevance theorists such as Carston (2002) and O'Donoghue (2009). That standard relevance-theoretic approach to simile and metaphor, and some of the criticism it has received will be presented in Section 4.1.

\section{Like in similes}

The above discussion shows that, on a number of approaches, similes and metaphors are regarded as related. On the other hand, the nature of relatedness is understood in several different ways: metaphors are conceived of as implicit similes, or similes are conceived of as implicit metaphors or metaphors and similes are two versions of the same (conceptual) phenomenon with similes being weaker, less obscure realizations. This shows that the role of like, the only formal item which makes simile statements different from their metaphorical equivalents, is far from clear. Either like is added in the comprehension process of metaphors or it is deleted in the comprehension process of similes, or its presence/absence brings about the weakening/strengthening of the impact of a given simile/metaphor.

Even though there has not been much discussion about the role of like in similes, several more or less explicit mentions of like can be found in the literature. For example, Ricoeur (2003: 293) argues that to be like "must be treated as a metaphorical modality of the copula itself" and that the like "is not just the comparative term among all the terms, but is included in the verb to be, whose force it alters". Feder Kittay (1987: 143, n. 1) also notices that like in simile should be understood metaphorically for it signals "comparisons which cross the bounds of our usual categories and concepts" (p. 19). In his interpretation of Aristotle's claims about metaphor and simile, Leezenberg (2001: 42) conjectures that the explicit term of comparison like is only a hedge weakening the assertive power of a statement. Thus, by saying Achilles is like a lion, "the speaker can avoid a commitment to the assertion that Achilles actually is a member of the class of lions, although both are species of the genus of brave animals" (Leezenberg 2001: 42). The hedging role of like is also suggested by Glucksberg (2001); on his account like is 
treated as a hedge reducing the perceived metaphoricity of non-literal comparison statements (Glucksberg 2001: 44). On the empirical side, the presence or the absence of the word like affects the number of features assumed by people to be shared by the topic/subject and the vehicle/predicate in nominal metaphors and similes. It has turned out that, in the case of metaphors, subjects are more likely to think that there are more common features between the two concepts involved than in the case of similes $(\mathrm{Xu}$ 2010: 1633).

\section{Like in relevance theory}

\subsection{Simile and metaphor in relevance theory}

To the best of my knowledge, there exists no exhaustive account of the preposition like used in similes from a perspective of relevance theory. However, it is possible to learn how this theory views like from the way it treats similes and metaphors. On the standard relevance-theoretic account (Carston 2002; see also O'Donoghue 2009), the interpretation of metaphors involves ad hoc concept formation, whereas the interpretation of similes does not. An ad hoc concept is an unlexicalised concept communicated by the speaker by means of a word encoding a related concept; such an unlexicalised concept has to be pragmatically constructed by the hearer in the process of utterance interpretation. An ad hoc concept may be narrower or broader than the lexically-encoded concept used for its communication, as illustrated by the use of bird in (5) and square in (6) below.

(5) The bird escaped its cage and flew out the window.

(6) His jaw is a square.

In (5), the concept BIRD is used to convey a more specific ad hoc concept BIRD* which denotes only birds kept in cages as pets. Such an ad hoc concept is the result of the lexical pragmatic process of narrowing, which involves "the use of a word to convey a more specific sense than the encoded one, with a more restricted denotation ..." (Wilson \& Carston 2007: 232). In (6), the geometric term square is used loosely to convey the sense of 'approximately a square': the broadened ad hoc concept SQUARE* is based on the lexically-encoded concept SQUARE 'a shape with four sides that are all the same length and four corners that are all right angles'. It shows that in the lexical pragmatic process of broadening, a word is used "to convey a more general sense than the encoded one, with a consequent expansion of the linguistically-specified denotation" (Wilson \& Carston 2007: 232).

In order to make sense of the metaphor in (7), one has to form an ad hoc concept based on the concept encoded by the word bulldozer.

(7) Mary is a bulldozer.

(8) Mary is like a bulldozer. 
The constructed ad hoc concept BULLDOZER* is both broader and narrower than the lexically-encoded concept BULLDOZER, whose denotation has been expanded to include obstinate and insensitive people and, at the same time, narrowed to exclude heavy machines. This shows that there is no overlap between the denotations of the lexicallyencoded concept BULLDOZER 'a piece of heavy machinery' and the derived ad hoc concept BULLDOZER* 'an obstinate and insensitive person' (Vega Moreno 2007: 97). By being described as a bulldozer, Mary is classified into the category of BULLDOZERS* 'obstinate and insensitive people'. In the simile in (8), however, as Carston (2002: 357358 ) argues, no ad hoc concept BULLDOZER* is communicated and the word bulldozer is understood as conveying the concept it encodes. If the lexically-encoded concept is preserved in similes, while it is not in metaphors, then there is no difference between similes and literal comparisons. Hence, we may assume that, on the standard relevancetheoretic approach, the like used in similes is the same as the one used in literal comparisons.

Such a diverse treatment of metaphors and similes is unacceptable for Hernández Iglesias (2010: 175-176), who puts forward the idea that similes, like metaphors, do involve ad hoc concept formation. He claims that Carston's account of similes is counterintuitive as it "draws too radical a difference between metaphors and similes and fails to account for what they have in common" (Hernández Iglesias 2010: 174). Carston (2002: 357) admits that the implicatures triggered by the metaphor and the corresponding simile (examples 7 and 8) "are probably the same" and ascribes the difference in their overall impact to the fact that metaphor is commonly felt "as somehow more direct and forceful." For Hernández Iglesias, it is implausible that such a difference would bring about the difference in what is explicitly communicated - the difference which seems to be a pivotal element in Carston's analysis. On her view, the metaphor in (7), which involves the ad hoc concept BULLDOZER*, would explicitly communicate that Mary is obstinate and insensitive, since ad hoc concepts are claimed to be part of what is explicitly communicated (explicature). In the case of the simile in (8), where no ad hoc concept is constructed, Mary's obstinacy and insensitiveness are implicated via the analysis of what Mary and literal bulldozers have in common. A related difficulty for Carston's account is that, in the right circumstances, a simile may be more powerful than the corresponding metaphor (see O'Donoghue 2009: 132).

Based on Carston's (2002: 359) observation that "longer stretches of the encoded conceptual structure" can be used metaphorically in order to create complex ad hoc concepts, Hernández Iglesias (2010: 175-176) puts forward the idea that to understand a simile of the form $X$ is like $Y$, it is necessary to construct the complex ad hoc concept [LIKE Y]*. This means that to understand a simile such as Mary is like a bulldozer, it is necessary to construct the complex ad hoc concept [LIKE A BULLDOZER]*, which means 'obstinate', 'single-minded', 'insensitive to other people's feelings', etc. He also claims that the process of constructing this complex ad hoc concept would be essentially the same as the construction of the ad hoc concept BULLDOZER* in the metaphor Mary is a bulldozer.

As noticed by Carston (2010: 255), Hernández Iglesias's proposal is problematic for a number of reasons. It does not follow from his cursory suggestion whether the ad hoc concept is broader or narrower than the string [LIKE A BULLDOZER]. Apparently, it has to be narrower since, from a literal point of view, everything is like everything else, and as 
Carston points out, it is hard to construct an ad hoc concept broader than the string [LIKE A BULLDOZER].

Although Hernández Iglesias's proposal is far from flawless, I think that he is correct to suggest an analysis of simile in terms of ad hoc concept formation (for an alternative proposal, see Wałaszewska 2010). Even Carston (2010: 255) is not fully opposed to the ad hoc concept treatment of simile, as can be seen from her comment on Hernández Iglesias's suggestion: "[It] is not that the key concept in the simile is never in any way pragmatically modulated ... but just that it does not undergo the radical broadening that the corresponding metaphorically used concept does..." However, what I find problematic in Hernández Iglesias's proposal is the function of LIKE in the ad hoc concept, which he does not examine in any way, though apparently he assumes that like in similes enters an ad hoc concept.

\section{2. 'Like' as a pragmatic marker}

Neither Carston's nor Hernández Iglesias's account of simile seems to provide a basis for a satisfactory explanation of the functioning of like in similes. There is, however, a detailed relevance-theoretic analysis of like as a pragmatic marker, to which I will now turn since it may prove insightful for an analysis of like as used in similes. Andersen (2001: 53) notes that the pragmatic marker like must have originated in a preposition with the meaning of 'similar to' and that the lexical predecessor of this pragmatic marker is still present in English as a preposition/(conjunction). It is worth mentioning that the pragmatic marker usage and the non-marker (preposition or conjunction) usage of like may be confused since the borderline between the two is fuzzy (Andersen 2001: 54). This could be illustrated with an exchange from Russo's (1997) Straight Man in which the sarcastic professor deliberately misinterprets the student's use of the pragmatic marker like as an attempt to produce a simile.

Student: 'I like the clouds ... They're, like, a metaphor.'

Professor: 'They are a metaphor ... If they were like a metaphor, they'd be, like, a simile' (Russo 1997, in Glucksberg \& Haught 2006: 360)

In his analysis of like as a pragmatic marker, Andersen (2001: 210) observes that it "is notorious for its functional complexity and distributional versatility" - it can be used as a quotative marker (ex. 9), approximator (ex. 10), marker of exemplification (ex. 11), discourse link (ex. 12) or hesitational device (ex. 13). Like may also accompany metaphors (ex. 14) and hyperboles (ex. 15).

(9) and then, and then Kevin came up to me and said erm ... if you if you go and see Mark this afternoon erm he would like to speak to you, I was like, he should come and speak to me. (Andersen 2001: 250)

(10) My lowest ever [score] was like forty. (Andersen 2001: 50)

(11) I know but it wouldn't be any point if someone wanted to be, like, a doctor and they got into a nursery place. (Andersen 2001: 236) 
(12) I know and like ... on Friday yeah I mean we're gonna be there for about an hour and a half probably yeah, and I wanna. (Andersen 2001: 255)

(13) Alright. Erm, well like, I usually take the train about ... twenty past. (Andersen 2001: 270)

(14) She's like tearing the wall down. (Andersen 2001: 236)

(15) We can like endlessly swear on it. (Andersen 2001: 236)

Andersen shows that like can affect utterance meaning in a number of ways, for example, by indicating the need for the broadening or narrowing of lexically-encoded concepts (Andersen 2001: 230). For example, in (10) like signals that the lexicallyencoded concept FORTY is used loosely as a crude approximation of the speaker's test score (p. 233). In (11), like triggers the process of ad hoc concept formation which results in the broadening of the lexicalised concept DOCTOR. Like before a doctor instructs the hearer to construct the ad hoc concept DOCTOR* which is broader than its lexically-encoded counterpart in that it denotes not only doctors but also other health care professionals. In this case, doctor is used to denote a broader category of professions related to health care of which this profession is the most salient member (pp. 236-237).

Andersen (2001: 210-211) claims that, despite the multitude of contexts in which it is used, like can be described in general terms as having the function of a marker which encodes a procedural constraint on utterance interpretation. In Andersen's (2001: 264) words, "[l]ike contributes to utterance interpretation and to the overall relevance of utterances as a procedural constraint on the process of identifying the intended explicatures of utterances", and it may, or may not, be truth-conditional.

At this point, it is worth clarifying the notion of a procedural constraint which follows from the relevance-theoretic distinction between conceptual meaning (concepts) and procedural meaning (procedures) (Blakemore 1987, 2002). Procedures are generally viewed as constraints on pragmatic inferencing which is involved in the interpretation of an utterance (Carston 2002: 57). A classic case of procedural encoding is the conjunction but, whose meaning guides the hearer through the comprehension process of the utterance in which it is present, by signalling the concept of contrast between the coordinated elements (Blakemore 2002: 90-91). Each of these two types of meaning may, or may not, be truth-conditional, in that each of them may, or may not, contribute to the proposition expressed (Bordería 2008: 1414). For example, discourse connectives such as so and after all are regarded as procedural and non-truth-conditional, since "they encode procedural constraints on implicatures" (Wilson \& Sperber 1993: 19) and they do not affect the truth-conditions for an utterance. On the other hand, illocutionary adverbs like seriously are seen as conceptual and procedural since they encode concepts but do not contribute to the truth-conditional content; they contribute to so-called higher-order explicatures, which carry information about the speaker's attitude to the speech act the speaker intends to perform. Mood indicators, interjections and intonation are also claimed to contribute to the construction of higher-order explicatures, but they encode procedures. Finally, pronouns such I and you or indexicals such as now or here are both procedural and truth-conditional in that they impose constraints on explicatures (see Wilson \& Sperber 1993; Bordería 2008). 
The idea of the conceptual/procedural dichotomy has been revisited on a number of occasions by various relevance theorists (see Bordería 2008: 1415-1416). Some of them suggest that the clear-cut binary distinction between conceptual and procedural meaning is hard to uphold; Moeschler (2002), for example, suggests that this distinction is gradual, which is reflected in the lexicon. A related view is presented by Takeuchi (1997), who shows, on the example of two Japanese causal connectives, that some words may encode both a concept and a procedure.

\section{Towards a new relevance-theoretic account of like in similes}

I agree with Andersen (2001: 53), that there exist two types of like: conceptual and procedural. Conceptual like is used in literal comparisons and is taken to mean 'similar to'. Procedural like is present in, for example, approximations and exemplifications and it instructs the hearer to construct an ad hoc concept by broadening or narrowing the concept(s) encoded by the linguistic material following like. What is more, Andersen (2001: 228) admits the possibility that like encodes both conceptual and procedural meaning; he assumes that like as a procedural marker "carries traces of an original lexical meaning, "similar to"" and suggests that "the notion of similarity is faintly present ... when like is used as a marker of loose use, approximation, exemplification".

I would like to claim that like in similes of the form $X$ is like $Y$ is both conceptual and procedural. It encodes the concept of similarity and a procedure which instructs the hearer to construct an ad hoc concept by broadening the concept encoded by (part of) the linguistic material after like. The broadened concept will help the hearer identify relevant properties attributable to the subject. As such like in similes is similar both to the conceptual like in literal comparisons, and to the procedural like functioning as a pragmatic marker.

Let me illustrate this suggestion by analysing the following oft-quoted example:

(16) My lawyer is like a shark.

The simile is likely to be interpreted along the following lines: 'My lawyer is a violent, cruel and rapacious person'. In order to arrive at this interpretation, it is necessary to construct an ad hoc concept based on the lexically-encoded concept SHARK. The concept SHARK will be, as indicated by like, broadened to include people - lawyers; however, there will be no narrowing. The broadened concept will be a kind of ad hoc superordinate category in which both literal sharks and lawyers can be found, allowing for a comparison of the two. What is more, the literal shark will be understood as the most salient, prototypical, member of the created category, in a sense, serving as a point of reference or comparison. The comparison of sharks and lawyers within the broadened category will show which properties are to be ascribed to the speaker's lawyer.

The above analysis shows how similes work and why they are intuitively felt to be intimately related to metaphors, on the one hand, and literal comparisons, on the other, as well as clearly distinct from both of them. What similes have in common with metaphors is that they likewise involve the process of ad hoc concept formation. And if they actually involve ad hoc concepts, this may explain why it is so easy to transform 
similes into metaphors by omitting like. However, the ad hoc concepts resulting from the use of a simile are different from those arising from the use of a metaphor; the former exploit broadening and the latter both broadening and narrowing. This hypothesis captures the intuition that metaphors are more abstract than similes. On the other hand, it is not too difficult to see what similes have in common with literal comparisons, namely the presence of like. However, it is argued that like operates differently in those two cases. In literal comparisons, like seems to encode the concept of similarity, whereas in similes the word appears to be both conceptual and procedural in nature; it encodes the concept of similarity and procedure to construct an ad hoc concept.

\section{Conclusion}

Assuming that similes are more related to metaphors than to literal comparisons, it makes sense to claim that like in similes introduces an ad hoc concept. Moreover, in similes, like is both conceptual and procedural, with the procedure it encodes instructing the hearer to construct an ad hoc concept by broadening the concept encoded by the expression following like. Such an account shows how similes are similar to and different from metaphors and literal comparisons. Namely, unlike literal comparisons, both metaphors and similes involve ad hoc concepts, even though the concepts are constructed differently. It also shows how the like used in similes is both similar to and different from the conceptual like used in literal comparisons and the procedural like functioning as a pragmatic marker.

\section{Notes}

1 It should be noted that Glucksberg (2008) has abandoned the view that similes should be interpreted as implicit metaphors.

\section{References}

Andersen, Gisle (2001). Pragmatic markers and sociolinguistic variation: A relevancetheoretic approach to the language of adolescents. Amsterdam \& Philadelphia: John Benjamins.

Aristotle (2007). In G. A. Kennedy (Ed.), Aristotle on Rhetoric: A theory of civic discourse. (2nd ed.). New York \& Oxford: Oxford University Press.

Beardsley, Monroe C. (1981). Aesthetics: Problems in the philosophy of criticism. (2nd ed.). Indianapolis, IN: Hackett.

Blakemore, Diane (1987). Semantic constraints on relevance. Oxford: Blackwell.

Blakemore, Diane (2002). Relevance and linguistic meaning. The semantics and pragmatics of discourse markers. Cambridge: Cambridge University Press.

Bordería, Salvador Pons (2008). "Do discourse markers exist? On the treatment of discourse markers in relevance theory". Journal of Pragmatics, 40, 1411-1434.

Bredin, Hugh (1998). "Comparisons and similes". Lingua, 105, 67-78. 
Carston, Robyn (2002). Thoughts and utterances. Oxford: Blackwell.

Carston, Robyn (2010). "Explicit communication and 'free' pragmatic enrichment". In B. Soria \& E. Romero (Eds.), Explicit communication: Robyn Carston's pragmatics (217-285). Houndmills, Basingstoke: Palgrave Macmillan.

Croft, William \& D. Alan Cruse (2004). Cognitive linguistics. Cambridge: Cambridge University Press.

Cruse, D. Alan (2006). A glossary of semantics and pragmatics. Edinburgh: Edinburgh University Press.

Feder Kittay, Eva (1987). Metaphor: Its cognitive force and linguistic structure. Oxford: Clarendon Press.

Glucksberg, Sam (2001). Understanding figurative language. Oxford: Oxford University Press.

Glucksberg, Sam (2008). "How metaphors create categories - quickly". In R. Gibbs (Ed.), The Cambridge handbook of metaphor and thought (67-83). Cambridge: Cambridge University Press.

Glucksberg, Sam \& Catrinel Haught (2006), "On the relation between metaphor and simile: When comparison fails". Mind \& Language, 21, 360-378.

Glucksberg, Sam \& Boaz Keysar (1993). "How metaphors work". In A. Ortony (Ed.), Metaphor and thought (401-424). (2nd ed.). Cambridge: Cambridge University Press.

Hernández Iglesias, Manuel (2010). “Ad hoc concepts and metaphor”. In B. Soria \& E. Romero (Eds.), Explicit communication: Robyn Carston's pragmatics (173-182). Houndmills, Basingstoke: Palgrave Macmillan.

Israel, Michael, Jennifer Riddle Harding \& Vera Tobin (2004). "On simile". In M. Achard \& S. Kemmer (Eds.), Language, culture, and mind (123-135). Stanford: CSLI Publications.

Lakoff, George \& Mark Turner (1989). More than cool reason: A field guide to poetic metaphor. Chicago: University of Chicago Press.

Leezenberg, Michiel (2001). Contexts of metaphor. Amsterdam: Elsevier.

Levinson, Stephen (1983). Pragmatics. Cambridge: Cambridge University Press.

Margolis, Joseph (1957). "Notes on the logic of simile, metaphor and analogy". American Speech, 32, 186-189.

Miller, George (1993). "Images and models, similes and metaphors". In A. Ortony (Ed.), Metaphor and thought (357-400). (2nd ed.). Cambridge: Cambridge University Press.

Moeschler, Jacques (2002). "Connecteurs, encodage conceptuel et encodage procédural". Cahiers de Linguistique Française, 24, 265-292.

O’Donoghue, Josie (2009). "Is a metaphor (like) a simile? Differences in meaning, effect and processing". UCL Working Papers in Linguistics, 21, 125-149.

Ortony, Andrew (1993). "The role of similarity in similes and metaphors". In A. Ortony (Ed.), Metaphor and thought (342-356). (2nd ed.). Cambridge: Cambridge University Press.

Ricoeur, Paul (2003). The rule of metaphor. The creation of meaning in language. Trans. by R. Czerny with K. McLaughlin \& J. Costello. London \& New York: Routledge.

Takeuchi, Michiko (1997). "Conceptual and procedural encoding: cause-consequence conjunctive particles in Japanese”. UCL Working Papers in Linguistics, 9, 1-24. 
Vega Moreno, Rosa E. (2007). Creativity and convention. The pragmatics of everyday figurative speech. Amsterdam \& Philadelphia: John Benjamins.

Wałaszewska, Ewa (2010). "Simile in relevance theory: Towards an alternative account". Acta Philologica, 38, 13-19.

Wilson, Deirdre \& Robyn Carston (2007). "A unitary approach to lexical pragmatics: Relevance, inference and ad hoc concepts". In N. Burton-Roberts (Ed.), Pragmatics (230-259). Houndmills, Basingstoke: Palgrave Macmillan.

Wilson, Deirdre \& Dan Sperber (1993). "Linguistic form and relevance". Lingua, 90, 125.

$\mathrm{Xu}, \mathrm{Xu}$ (2010). "Interpreting metaphorical statements". Journal of Pragmatics, 42, $1622-1636$.

\section{About the author}

Ewa Walaszewska is Assistant Professor at the Institute of English Studies, University of Warsaw. Her principal interests lie within the fields of semantics and pragmatics, including relevance theory, its applications to the study of particular linguistic phenomena as well as its theoretical implications for the investigation of human communication and cognition. She has published internationally with Cambridge Scholars Publishing and Journal of Pragmatics. 